\title{
Subjetividade no uso de adverbiais modalizadores em artigos de opinião
}

\author{
Subjectivity in the use of modal adverbs in opinion articles
}

\author{
Dennis Castanheira* \\ dennisscastanheira@gmail.com \\ Universidade Federal do Rio de Janeiro \\ Maria Maura Cezario ** \\ mmcezario@gmail.com \\ Universidade Federal do Rio de Janeiro
}

\begin{abstract}
RESUMO: Este artigo visa a análise dos usos de adverbiais modalizadores como elementos subjetivos a partir de uma amostra composta por artigos de opinião dos jornais O Globo Online e O Dia Online. Como fundamentação teórica, recorremos aos pressupostos do Funcionalismo norte-americano, mais especificamente aos estudos sobre subjetividade, de Traugott e Dasher (2002) e Traugott (2010) e ao arcabouço da Linguística do Texto (VAN DIJK, 1997), considerando, sobretudo, as investigações sobre articulação textual, de Koch (2003) e Campos e Torquato (2013). Nossos resultados apontam para um continuum de subjetividade relacionado aos seus efeitos de sentido e para a estreita relação dos usos dos adverbiais modalizadores com o gênero textual estudado.
\end{abstract}

PALAVRAS-CHAVE: Adverbiais modalizadores. Subjetividade. Articulação textual. Artigos de opinião.

ABSTRACT: This article aims to analyze the uses of modal adverbs as subjective elements in a sample composed of opinion articles from O Globo Online and O Dia Online newspapers. We used the assumptions of North American Functionalism, more specifically we dealed with Traugott and Dasher' (2002) and Traugott' (2010) studies on subjectivity; we also used the Text Linguistics framework (VAN DIJK, 1997), considering, above all, the investigations on textual articulation, by Koch (2003) and Campos and Torquato (2013). Our results point to a continuum of subjectivity related to its effects of meaning and to the strong relation between the uses of the adverbs and the textual genre studied.

KEYWORDS: Modal adverbs. Subjectivity. Textual articulation. Opinion articles.

\footnotetext{
* Professor Substituto de Língua Portuguesa, Doutorando em Língua Portuguesa, Mestre em Linguística e Graduado em Licenciatura em Letras pela Universidade Federal do Rio de Janeiro.

** Professora Doutora do Departamento de Linguística e Filologia e do Programa de Pós-Graduação em Linguística da Universidade Federal do Rio de Janeiro. Líder do Grupo de Estudos Discurso \& Gramática (RJ). Bolsista de Produtividade do CNPq nível 2.
} 


\section{Introdução}

Neste artigo, apresentaremos, sob uma perspectiva funcional e textual, um estudo acerca do uso de adverbiais modalizadores em artigos de opinião, com o objetivo principal de verificar como esses elementos são usados subjetivamente nesse gênero. Os adverbiais incluem os advérbios (talvez, provavelmente, quase) e as locuções adverbiais (com certeza, sem dúvida) e têm diversos papéis no texto, conforme será visto ao longo do artigo.

De acordo com Martelotta (2012), a categoria dos advérbios engloba elementos muito heterogêneos que, por isso, precisam ser investigados de forma separada. As pesquisas já desenvolvidas sobre a classe, em geral, apresentam, ou caráter (sócio) funcionalista, buscando as motivações para o posicionamento sintático dos adverbiais na oração (cf. ILOGTI DE SÁ, 2015; CEZARIO et alii [no prelo]), ou trabalham o papel dos advérbios e das locuções adverbiais na coconstrução de sentidos a partir de processos sociocognitivos como a referenciação e a sequenciação (cf. KOCH, 2003; CAVALCANTE, 2011).

A pesquisa aqui desenvolvida busca relacionar esses elementos gramaticais com o gênero textual em que eles estão sendo analisados. Verificamos, a partir da literatura, que os adverbiais modalizadores são articuladores textuais argumentativos e, por isso, optamos por analisar seu uso em um gênero mais ligado à argumentação, mais especificamente, o gênero artigo de opinião. ${ }^{1}$

Adotamos, como concepção teórica, uma associação pouco explorada nos estudos linguísticos: a união entre o Funcionalismo norte-americano e a Linguística do Texto. Essas correntes investigam as situações efetivas de usos, considerando aspectos relacionados ao contexto comunicativo, à interação e à sociocognição.

Com relação à metodologia, coletamos e analisamos dados com adverbiais modalizadores e observamos a relação entre a subjetividade e os efeitos de sentido desses elementos em dois jornais: O Globo Online e O Dia Online. Para investigar esses aspectos, a seguinte hipótese norteia este artigo: num continuum categorial, os adverbiais modalizadores terão efeitos de sentido mais subjetivos.

Na seção seguinte deste trabalho, apresentaremos a fundamentação teórica do trabalho com duas subseções: subjetividade em perspectiva funcional e

1 Este artigo traz parte dos resultados apresentados na Dissertação de Mestrado de Castanheira (2017). 
articulação textual. $\mathrm{Na}$ seção 2, discutiremos algumas características do gênero artigo opinativo. Na seção seguinte, apresentaremos a metodologia e a análise dos dados. Por fim, finalizaremos o artigo com algumas conclusões e perspectivas futuras de análise.

\section{Fundamentação teórica}

\subsection{Subjetividade em perspectiva funcional}

Na perspectiva teórica do Funcionalismo norte-americano (GIVÓN, 1990; 1995), a língua é um instrumento de interação social proveniente do uso, existindo, portanto, para um determinado propósito comunicativo. A comunicação existe não apenas para transmitir/ receber uma informação, mas para que determinados objetivos do falante/ouvinte sejam cumpridos. Caso queira, por exemplo, convencer o interlocutor de algo, o falante usará estratégias linguístico-discursivas específicas para que isso ocorra.

Para o Funcionalismo americano, então, a linguagem não é um fenômeno isolado, servindo, na verdade, a variadas intenções. Assim, é importante, numa análise funcional, considerar os usos na interação verbal, englobando o componente pragmático a questões sintáticas, morfológicas, fonológicas e/ou semânticas. A compreensão das ocorrências linguísticas só é possível a partir de suas funções dentro dos contextos em que estão inseridas.

Alguns estudos funcionalistas recentes, sobretudo os de Elizabeth Traugott, têm enfocado num aspecto da linguagem humana: a subjetividade. Traugott e Dasher (2002) apontam que a subjetividade só passou a ser um tópico importante para a comunidade científica internacional a partir dos postulados de Benveniste (1976). Segundo o autor, a linguagem só pode ser tratada como tal caso seja marcada por profundas marcas de subjetividade. Traugott e Dasher (2002) também o retomam para definir discurso e debater o conceito de intersubjetividade. De acordo com Benveniste (1976), o discurso é a língua à medida que esta é assumida pelo falante diante do estabelecimento de intersubjetividade, condição para existência da comunicação.

Para Traugott e Dasher (2002) e Traugott (2010), na dinâmica da produção oral ou escrita, os recursos linguísticos podem ser usados de diversas maneiras para 
expressão da subjetividade. Segundo os autores, há produtores mais ou menos conscientes das marcas utilizadas: produtores mais criativos tenderiam a saber usálas de forma mais cuidadosa do que os demais. As escolhas lexicais estariam ligadas à natureza do registro e seu grau de monitoramento. Assim, a escrita acadêmica, por exemplo, seria mais marcada por traços objetivos. Em ambos os casos, contudo, as estratégias usadas são provenientes da intenção do produtor e da forma como essa intencionalidade é codificada.

Segundo Traugott e Dasher (2002), a subjetividade envolve um sujeito que desenvolve uma visão subjetiva dos fatos, representando-a no discurso. Os autores opõem subjetividade à objetividade, destacando que o ponto de vista objetivo ocorre quando o falante tenta se posicionar de forma imparcial, descrevendo os fatos como eles ocorreram efetivamente no universo biossocial.

É evidente, contudo, que não há objetividade completa na linguagem, pois sempre há algum grau de subjetividade, por mais o falante/escritor tente escondê-lo em sua produção por meio de algumas estratégias linguístico-discursivas. Sua expressão ocorre para determinados fins comunicativos e é expressa por sujeitos com intuito de convencimento e persuasão, o que configura inquestionável subjetividade. Cabe a estudos como o nosso a identificação das marcas que indicam, de alguma forma, o posicionamento do sujeito em relação ao que está sendo enunciado.

Traugott e Dasher (2002) também adotam essa perspectiva, apontando para a necessidade de estabelecimento de um continuum entre formas subjetivas e objetivas, proposta que adaptamos neste trabalho. Há, segundo os autores, marcas específicas de cada um dos pontos. São caracterizadas como expressões dotadas de maior subjetividade aquelas com: (i) dêixis espacial e temporal explícitas; (ii) marcadores explícitos da atitude do sujeito em relação à proposição; (iii) marcadores explícitos da atitude do falante/ escritor em relação à estrutura do discurso.

Traugott e Dasher (2002) apontam, ainda, que as escolhas dos falantes/ escritores dentro desse continuum podem estar relacionadas aos papéis sociais exercidos por eles. Nas sociedades americana e europeia, por exemplo, figuras que ocupam posições de autoridade costumam ter um discurso mais marcado pela objetividade, ao passo que pessoas com menor poder, ou que querem demonstrar menos sua posição superior, tendem a usar uma linguagem mais subjetiva. Em outras sociedades, porém, essa tendência pode não se confirmar, o que reitera o 
caráter pragmático e sociocognitivista da subjetividade.

\subsection{Articulação textual}

Também utilizamos como fundamentação teórica a Linguística do Texto (LT), perspectiva que em muitos aspectos está relacionada com o Funcionalismo, sobretudo por estudar a língua em uso e verificar as relações entre forma e função em porções comunicativas maiores do que a oração.

Segundo Koch ([2004] 2015), o objeto de estudo da LT é o texto e, consequentemente, as relações nele presentes. A LT caracteriza-se, atualmente, por uma abordagem sociocognitiva e interacional. $O$ texto hoje é tido não como um produto do ato comunicativo, mas como um complexo processo sociocognitivo. Os sentidos, nessa perspectiva, não estão no texto, havendo apenas pistas textuais que auxiliam em sua coconstrução. Só é possível compreender algumas de suas acepções diante do contexto comunicativo em que o texto está inserido. Cabe, à LT, então, a descrição e a atualização dos processos envolvidos na compreensão e na produção textual, considerando os conhecimentos linguísticos, enciclopédicos, intertextuais e contextuais. O texto é concebido como "um evento comunicativo em que estão os elementos linguísticos, visuais e sonoros, os fatores cognitivos e vários aspectos" (CAVALCANTE, 2011, p. 20). Os sentidos são construídos na interação entre o texto e os sujeitos, não sendo, então, preexistentes ao ato da interação e, portanto, independentes do leitor.

Neste artigo, destacamos, especificamente, o papel de articuladores textuais desempenhado pelos adverbiais modalizadores. Segundo Koch (2003), o encadeamento de segmentos ou porções textuais de qualquer extensão é feito, na maioria dos casos, por elementos linguísticos denominados pela LT como articuladores textuais, ligando "períodos, parágrafos, subtópicos, sequências textuais ou partes inteiras do texto" (KOCH, 2003, p. 133), contribuindo para a construção de um texto coeso e coerente. Os articuladores são marcadores que desempenham papel importante no texto, elementos que, segundo Santos (2003), englobam um caráter coesivo que garante a progressão textual, além de apresentarem nuances diversas em seus sentidos, diante do contexto em que estão inseridos.

De acordo com Koch (2003, p. 133), eles são responsáveis por 
relacionar elementos de conteúdo, ou seja, situar o estado de coisas de que o enunciado fala no espaço e/ou no tempo, bem como estabelecer entre eles relações de tipo lógico-semântico; podem estabelecer relações entre dois os mais atos de fala, exercendo funções enunciativas ou discursivo-argumentativas; e podem, ainda, no texto, desempenhar funções meta-enunciativas.

Os articuladores textuais, então, são "conectores" que estão envolvidos no processo de encadeamento textual a partir de determinadas estratégias de sequenciação ancoradas em marcas linguísticas específicas que colaboram para a progressão do texto. Para que a sequenciação seja garantida, segundo Koch (2003), é possível utilizar estratégias de diferentes níveis - fonético-fonológico, sintático, semântico. Podem ser efetuadas, ainda, recorrências de vários tipos, dentre as quais a reiteração de itens lexicais, de elementos fonológicos, de tempos verbais, além de paralelismos e paráfrases.

Campos e Torquato (2013) apontam que, dentre os vários mecanismos responsáveis pelo processo de sequenciação, está a articulação textual argumentativa. De acordo com os autores, para estudar os articuladores argumentativos, a LT recorre aos estudos da Semântica Argumentativa, de Oswald Ducrot, incorporando algumas premissas, como a acepção de que a argumentação está na língua, sendo tecida por elementos discursivo-argumentativos que orientam os sentidos para o interlocutor e marcam subjetivamente o texto, constituindo os denominados articuladores textuais, operadores de discurso ou operadores argumentativos. As investigações da LT, contudo, utilizam a nomenclatura "articuladores textuais", também adotada nesse trabalho.

Os articuladores argumentativos englobam diferentes grupos de elementos linguísticos, como as conjunções e os advérbios. Para Koch (2003) e Koch e Elias (2016), esses articuladores têm diversas funções pragmático-discursivas definidas pelo tipo de relação estabelecida, contextualmente, entre as unidades articuladas e pelos níveis estruturais em que se inscrevem essas mesmas unidades. Algumas dessas funções são: introduzir relações discursivo-argumentativas de contrajunção, justificativa, explicação, generalização, comprovação; "comentar" a própria enunciação a partir de delimitações, marcação de atitude, demonstração de afetividade, preservação de faces, indicação de graus de imperatividade; organizar o texto; situar ou ordenar o estado de coisas de que o enunciado fala no espaço e/ou no tempo; estabelecer relações lógico-semânticas. Essas funções são ligadas, pelas 
autoras, aos itens adverbiais (sobretudo os modalizadores) e às conjunções. Adotamos essa proposta nesse trabalho, considerando os adverbiais modalizadores ("talvez", "provavelmente", "com certeza") como articuladores meta-enunciativos (KOCH, 2003).

\section{0 gênero artigo opinativo}

De acordo com Bakhtin ([1979] 1997), os gêneros são formas relativamente estáveis estabelecidas como práticas sócio-históricas e podem ser analisados a partir de três critérios: conteúdo temático, estilo e construção composicional. O conteúdo temático engloba do que trata o gênero, ou seja, o que é dito e o que pode ser dito nele; o estilo compreende as seleções lexicais e aos aspectos gramaticais; a construção composicional representa a estruturação e o enquadramento formal, o que engloba as tipologias textuais e as partes constitutivas de cada gênero.

Além desses conceitos, é preciso considerar, ainda, aspectos como o domínio discursivo e o suporte a que os gêneros se vinculam. Segundo Marcuschi (2008), o domínio é a esfera de produção de cada gênero (jornalístico, religioso, literário) e o suporte é o locus físico ou virtual do gênero, ou seja, onde ele é veiculado (jornal, revista, muro, livro didático). Os artigos opinativos são caracterizados por seu caráter fortemente argumentativo, pertencendo, predominantemente, ao domínio jornalístico e sendo veiculados em diferentes suportes textuais, como discutiremos ao longo desta seção.

De acordo com Boff, Köche e Marinello (2009), os artigos de opinião partem da argumentação para analisar, avaliar e responder questões controversas e atuais discutidas socialmente. Esses artigos são escritos por articulistas, muitas vezes autoridades nos assuntos sobre os quais estão escrevendo. $O$ enfoque dos artigos opinativos não é a apresentação de acontecimentos e fatos, mas sua análise, marcando o posicionamento do enunciador em relação ao que está sendo tratado. Sua publicação geralmente está vinculada a seções opinativas com periodicidade regular em sua publicação e espaço físico limitado. Para Boff, Köche e Marinello (2009), sua produção deve considerar que os leitores já apresentam opiniões prévias sobre o que será defendido e que as teses apresentadas devem considerar, em alguma medida, essas opiniões, omitindo-as ou antecipando possíveis respostas.

Para esses autores, os artigos opinativos apresentam uma estrutura regular: 
situação-problema, discussão e solução-avaliação. A situação-problema engloba a apresentação da questão a ser debatida ao longo do texto, contextualizando o assunto, podendo evidenciar o objetivo da argumentação a ser desenvolvida ou da relevância na discussão do tema. A discussão, por outro lado, é caracterizada pela argumentação e construção da tese acerca do tema analisado, apresentando fatos, "argumentos de autoridade", exemplos a partir de trechos marcados por outras tipologias textuais. Já a solução-avaliação é uma resposta ao que foi apresentado, reafirmando a tese defendida, sem apenas resumir ou reafirmar o que foi afirmado anteriormente.

Segundo Melo (2015), o gênero artigo de opinião está presente em diversas esferas da comunicação humana, apresenta forte caráter sociodiscursivo e circula em diferentes suportes textuais. Assim, de acordo com a autora, os artigos opinativos são típicos de variados domínios discursivos: jornalístico, religioso, político, científico, etc. Além disso, esse gênero é caracterizado "pela defesa de um posicionamento sobre determinada temática, o qual relaciona o ponto de vista de um sujeito que pode ou não concordar com o tema abordado" (MELO, 2015, p. 73).

Para Bräkling (2000), esse gênero tem como característica a busca pelo convencimento do interlocutor acerca da tese defendida, influenciando e transformando suas perspectivas a partir dos argumentos apresentados. Para isso, são utilizadas, segundo Boff, Köche e Marinello (2009), diferentes estratégias que ajudam na tentativa de persuadir o leitor. Algumas delas são: o uso de outras "vozes" a partir de "argumentos de autoridade", ou seja, depoimentos/ opiniões de pessoas que tenham grande conhecimento do assunto tratado; apoio em fatos que corroboram a validade do que é dito. Dessa forma, haverá maior adesão do leitor em relação à tese apresentada.

De acordo com Dolz e Schneuwly (2004), os artigos de opinião tem como tipologia predominante a argumentação tendo em vista seu objetivo de convencimento junto ao público leitor. Bräkling (2000) aponta, ainda, que há pistas textuais típicas desse gênero: presente do indicativo ou subjuntivo na exposição dos argumentos, uso da terceira pessoa ao longo do texto e presença de articuladores argumentativos, que contribuem para construção da argumentação. Os elementos aqui estudados, como já expusemos, funcionam como articuladores textuais argumentativos e, portanto, são importantes na construção desse gênero textual. 


\section{Metodologia e análise de dados}

\subsection{Metodologia}

Estabelecemos neste artigo uma análise qualitativa e quantitativa baseada em uma amostra compostas por jornais, pois esse é um gênero recorrente nesse suporte. A opção pelos jornais O Globo Online e O Dia Online foi motivada pela periodicidade na publicação de artigos de opinião nesses jornais; já a escolha pelas versões online relaciona-se ao acesso mais facilitado aos textos usados na amostra constituída para o artigo. Ao todo, analisamos o uso dos adverbiais modalizadores em 60 artigos de opinião, 30 do jornal O Globo Online e 30 do jornal O Dia Online. Coletamos todos os dados presentes nesses textos, totalizando 74 adverbiais.

O foco metodológico deste artigo é a análise do grau de subjetividade dos adverbiais modalizadores. Para isso, primeiramente analisamos qualitativamente os dados investigando quais efeitos de sentido eles veiculavam. Diante dessa análise, os dividimos em cinco grupos (epistêmico, deôntico, afetivo, delimitador e axiológico) que, posteriormente, relacionamos aos graus de subjetividade envolvidos em sua produção, resultando numa proposta de gradiência de subjetividade apresentada na subseção seguinte. Posteriormente, observamos quantitativamente a frequência desses efeitos e a possível influência do veículo no uso desses elementos.

Ressaltamos que não temos como objetivo apresentar uma visão categórica sobre o uso desses elementos, nem defender que no gênero artigo de opinião esses usos são categoricamente mais recorrentes, pois reconhecemos a complexidade de caracterizar determinados usos relacionados a um gênero. Para isso, é necessário obter uma amostra mais ampla, que apresente diferentes suportes, veículos, etc. Por isso, buscamos, na verdade, relacionar os usos ao gênero, ao suporte e aos veículos utilizados, encontrando possíveis relações, sem taxá-las, contudo, como categóricas.

\subsection{Análise}

Postulamos inicialmente que os adverbiais modalizadores veiculariam efeitos de sentido mais subjetivos. Essa hipótese se vincula ao gênero artigo opinativo tendo em vista que é esperado que, em textos que expressem maior opinião, haja 
marcas mais subjetivas do que em textos pouco opinativos como as notícias, por exemplo. Para teste dessa hipótese, retomamos o trabalho de Koch (2003) sobre articulação textual e observamos quais efeitos de sentido eram veiculados pelos modalizadores, tidos pela autora como articuladores metaenunciativos, ou seja, os que "comentam" a enunciação. O agrupamento feito neste trabalho não compreende uma repetição da proposta de Koch (2003), mas, na verdade, uma adaptação, um reagrupamento de acordo com os dados que encontramos, o que pode ser visto nos exemplos a seguir:

a) Epistêmico: demonstra o grau de comprometimento/ engajamento do enunciador e o grau de certeza em relação ao que está sendo enunciado.

(1) "Isso os jornais estrangeiros ainda não registraram, eles, que estão implicando tanto com nossa maneira de torcer, e até de comer: esta Olimpíada talvez seja a mais liberada que já existiu em termos de comportamento" (Artigo "Sem culpa ou preconceito" - Jornal O Globo Online).

(2) "O gesto político de repercussão nacional, certamente, já está provocando frutos no encaminhamento do ordenamento das contas estaduais, evidenciando a gravidade do momento e da importância dos altos mandatários se preocuparem menos com a próxima eleição e mais com o futuro do país" (Artigo "O grito do Rio" Jornal O Dia Online).

Nos exemplos acima, apresentamos casos de modalizadores que veiculam efeito de sentido epistêmico. Em (1), o enunciador constrói seu texto apresentando uma crítica à imagem construída pela imprensa estrangeira em relação ao comportamento dos brasileiros nas olimpíadas, incluindo sua torcida e sua forma de alimentação. Posteriormente, busca um argumento contra os julgamentos midiáticos em relação ao evento, afirmando que seriam os jogos com maior liberdade comportamental. Contudo, utiliza o modalizador "talvez", possivelmente como uma estratégia atenuativa, relativizando, sendo menos categórico e, portanto, apresentando menor grau de certeza e comprometimento. Já em (2), há o modalizador "certamente", que indica um posicionamento bem mais assertivo, categórico em relação à proposição: as consequências da repercussão nacional do gesto político. O grau de certeza e comprometimento é muito maior da mesma forma que o grau de engajamento, o que contribui para a construção de uma argumentação mais marcada subjetivamente e possivelmente mais transparente ao 
leitor.

b) Deôntico: indica o grau de imperatividade/ facultatividade dos enunciados.

(3) "Sempre que ouvimos uma dessas canções para se sentir bem, nos imaginamos num pôr de sol de uma praia idílica, a correr de braços abertos em direção ao ser amado, como nos mais contundentes comerciais de cigarro de antigamente. É como se o pôr do sol, a praia idílica e o ser amado só nos fossem permitidos nesses momentos de alienação e fantasia. Na real, não temos direito a nada disso, porque nos disseram que o prazer não presta, e o mundo é necessariamente um vale de lágrimas. O contrário do que está, por exemplo, na difamada 'what a wonderful world"' (Artigo "Um mundo maravilhoso" - Jornal O Globo Online).

(4) "Imagine-se a situação de um proprietário que tem a sua terra invadida, enquanto decisões judiciais de reintegração de posse não são cumpridas. O Pará é um estado que vive uma enorme crise, em uma situação que poderíamos caracterizar como a de uma terra sem lei. Um tal mecanismo de obtenção de terras, a preços vigentes, e com pagamento em dinheiro - e não necessariamente mediante TDAs (Títulos da Dívida Agrária) - seria um instrumento que poderia facilitar o equacionamento de tais conflitos, além, evidentemente, de um maior respeito à lei, não seguida em vários estados do país. Seriam compras nas condições de uma economia de mercado" (Artigo "Incra" - Jornal O Globo Online).

Nos exemplos (3) e (4), percebemos que há o uso de modalizadores que apresentam efeito deôntico. Em (3), o adverbial "necessariamente" indica como o mundo é: um vale de lágrimas. Seu uso é relacionado ao que já vem sendo construído por outras pistas textuais no artigo em questão. A ideia de o mundo como um local ruim é montada a partir da ausência de direitos, da ideia de que o prazer é algo negativo, o que leva o mundo a ser fatalmente um vale de lágrimas, ou seja, um local de tristeza e desânimo. Nesse exemplo, podemos perceber que o modalizador "necessariamente" indica a imperatividade do que está sendo enunciado, afirmando que certamente o mundo será da forma enunciada. No exemplo (4), o modalizador "necessariamente" é utilizado pelo enunciador para indicar o grau de facultatividade do enunciado, demonstrando que não é obrigatório que haja Títulos da Dívida Agrária para que haja obtenção de terras a preços vigentes. Vale ressaltar que, embora os exemplos (3) e (4) apresentem o mesmo modalizador, a pista textual "não" orienta a argumentação para um caminho diferente no exemplo (6).

c) Afetivo ou atitudinal: encena a atitude psicológica do enunciador em relação ao 
evento enunciativo.

(5) "Lamentavelmente, a maioria das agências hoje existentes, em particular as municipais, não se enquadra nesse figurino e, por uma questão de escala, jamais se enquadrará" (Artigo "Caminhos para privatização" - Jornal O Globo Online).

(6) "Houve quase 14 mil amputações e mais de 40 mil fraturas. O que justificaria afrouxar as normas, beneficiando (pra variar) os empresários em detrimento dos trabalhadores? Infelizmente, se faz necessário estarmos atentos a iniciativas que vão contra a vida dos trabalhadores" (Artigo "Retrocesso nas normas de segurança do trabalho" - Jornal O Dia Online).

Nos exemplos (5) e (6), há casos que identificamos efeito de sentido afetivo. Em (5), o adverbial "lamentavelmente" marca o posicionamento do enunciador em relação às agências brasileiras atuais. Esse modalizador não apenas marca a subjetividade, demonstrando, além desse efeito, uma avaliação negativa em relação às agências nacionais. No exemplo (6), o modalizador "infelizmente" também marca um posicionamento negativo em relação ao fato apresentado: a necessidade de atenção em relação às iniciativas contra a vida dos trabalhadores. Em ambos os casos, os modalizadores apresentam um posicionamento claro do enunciador em relação à proposição. Contudo, é necessário destacar a escolha de bases adjetivas ligadas às emoções, como "infeliz" e "lamentável", que apresentam uma avaliação mais passional, causando um efeito discursivo também calcado na intersubjetividade entre escritor e leitor.

d) Delimitador ou hedge: explicita o âmbito do conteúdo enunciado.

(7) "Para ilustrar, mencionamos que a politicamente correta isenção das mercadorias da cesta básica é um benefício autorizado pelo Confaz. Portanto, para dar a César o que é de César, é necessário excluir $75 \%$ dos incentivos concedidos naquele período, já que decorrem de tais dispositivos legais" (Artigo "Manicômio tributário, o retorno" - Jornal O Dia Online).

(8) "O Estado brasileiro historicamente ignora grandes partes das cidades, compostas pelos bairros populares, localizados em geral, mas não só, no que hoje chamam por periferias" (Artigo "Reunião de cúpula" - Jornal O Globo Online).

Nos exemplos (7) e (8), encontramos alguns modalizadores com efeito discursivo delimitador. Em (7), o adverbial destacado delimita que a isenção das 
mercadorias da cesta básica é "politicamente correta". É importante ressaltar que, nesse caso, o adverbial assume um sentido além do seu original; "politicamente" não se refere a um aspecto político stricto sensu, mas há algo mais amplo, social, negociado entre os cidadãos em sociedade. A combinação com outra pista textual "correta" - reforça esse novo sentido do modalizador "politicamente". Casos de modalizadores apresentando novos papéis semânticos também foram defendidos por Castilho e Castilho ([1992] 2002) a partir das classificações prototípico, paragógico e complexo. Em (8), o modalizador "historicamente" delimita a ausência de prioridade em relação a algumas partes da cidade, apontando que é uma questão histórica, que não ocorre apenas atualmente, mas sistematicamente. Logo após, a locução "em geral" também delimita, em alguma medida, que há uma problemática geralmente mais ampla nos bairros periféricos. Além de delimitar, o adverbial "historicamente" constrói o texto argumentativamente, mostrando o descaso do estado com a população há muitos anos, o que é complementado com a locução "em geral", que aponta para um descaso sobretudo com a população mais pobre.

e) Axiológico: representa a valoração em relação ao enunciado.

(9) "Aqui, dois 'detalhes' se destacam imperiosamente: as regras explícitas e um uso do corpo com foco exclusivo no seu desempenho, talento e capacidade. No caso, uma refrega do atleta-herói contra o tempo, o espaço e os "estrangeiros" - esses outros que, paradoxalmente, não podem ser eliminados" (Artigo "Detalhes olímpicos" - Jornal O Globo Online).

No exemplo (9), o único com adverbial modalizador axiológico encontrado na amostra, percebemos o uso do modalizador "paradoxalmente", que, além de contribuir para a construção coesiva do texto, indica a avaliação do enunciador em relação aos problemas enfrentados pelos atletas nas olimpíadas. Há um julgamento, indicando que é paradoxal a impossibilidade de eliminar alguns percalços de sua trajetória, ideia reforçada por outra pista textual: a expressão "atleta-herói". Os axiológicos apresentam um posicionamento mais claro do enunciador, com alto grau de subjetividade, mas são menos subjetivos do que os afetivos ao trazer bases adjetivas ligadas às emoções, o que possivelmente causa no leitor menos efeitos discursivos.

Após a observação dos dados, percebemos que alguns desses efeitos são 
mais subjetivos do que outros. Postulamos, então, com base na análise e na literatura, o seguinte continuum:

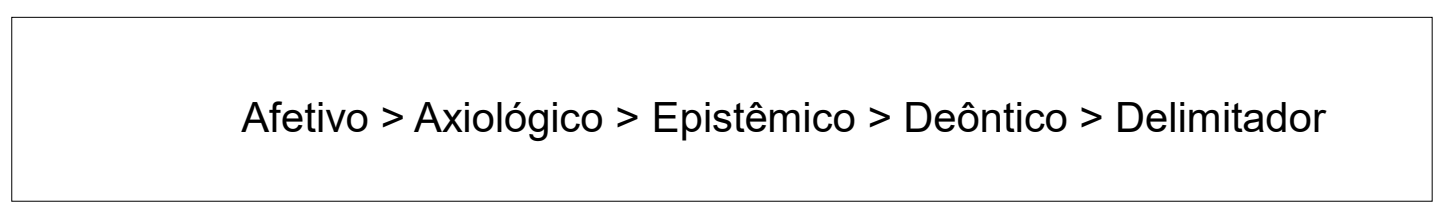

Mais subjetivos

Menos subjetivos

Seguindo esse continuum, teríamos, no polo dos mais subjetivos, exemplos como:

(10) "Dornelles, além de preparado como economista e professor, alto funcionário de carreira do Ministério da Fazenda, é político nato, tendo exercido muito jovem a função de secretário particular do primeiro-ministro, seu tio Tancredo Neves. Seu pai, general Mozart Dornelles, fez carreira militar e de gestor público respeitado. O tio Ernesto, também militar, foi governador e senador pelo Rio Grande do Sul. Não poderia ter tido melhor escola e melhores mestres. Exemplo, infelizmente, raro na política, tem sido de extrema correção com o governador licenciado, mostrando na postura discreta, mas firme, ao enfrentar a tormenta, a grandeza do homem público e da figura humana" (Artigo "O grito do Rio" - Jornal O Globo Online).

Nesse exemplo, temos o adverbial modalizador "infelizmente" marcando de forma clara o posicionamento do enunciador em relação à postura dos políticos no Brasil. Ele lamenta por poucos políticos terem o preparo e as atitudes do vicegovernador Francisco Dornelles, ressaltando o quão discreto e firme ele é; o que demonstra, para ele, que o político é um homem grandioso na política e na vida. $O$ modalizador reforça subjetivamente o discurso do enunciador, mas ancora-se em outras pistas textuais, ou seja, em outras marcas linguísticas como os adjetivos "raro", "extrema", "discreta" e "firme", que, colaboram na construção de sua argumentação, construindo uma cadeia argumentativa mais sólida, que engloba aspectos profissionais e pessoais. Dessa forma, a imagem de Dornelles, que já vinha sendo construída ao longo do texto, como um homem bem preparado ("economista", "professor", "alto funcionário do ministério da fazenda") e talentoso ("político nato"), passa a ser defendida e construída com mais clareza a partir do articulador argumentativo "infelizmente".

Já no polo menos subjetivo, teríamos casos como: 
(11) "Em um cenário com dados alarmantes de acidentes na indústria, divulgados pelo Ministério do Trabalho e Previdência Social, é no mínimo contraditória a atitude do governo interino de ceder aos empresários. Somente de 2011 a 2013 foram cerca de 600 mortes por causa desse tipo específico de acidente, uma a cada 44 horas. Houve quase 14 mil amputações e mais de 40 mil fraturas. $O$ que justificaria afrouxar as normas, beneficiando (pra variar) os empresários em detrimento dos trabalhadores?" (Artigo "Retrocesso nas normas de segurança do trabalho" - Jornal O Dia Online).

Nesse exemplo, o adverbial modalizador "quase" atua na construção argumentativa do texto delimitando a quantidade de amputações no período de 2011 a 2013. O modalizador, além de delimitar, também atua na intensificação do valor, já que não o especifica completamente, causando uma impressão de que há ainda mais amputações. Se fosse usado um número exato, haveria menor efeito discursivo no leitor. Da mesma forma, posteriormente, é utilizado o intensificador "mais" para designar as faturas, deixando claro que essas pistas textuais colaboram para a construção da tese do texto de que a atitude do governo em ceder aos empresários é contraditória.

É preciso ressaltarmos, ainda, que as categorias apresentadas são fluidas e englobam elementos diferentes, com complexidades estruturais, pragmáticas e cognitivas distintas. No exemplo a seguir, podemos observar essa questão:

(12) "O Réveillon seria uma espécie de início das libações que só se encerram na Quarta-Feira de Cinzas, em grande estilo. Para ser exato, devo confessar que não é exatamente de Carnaval que eu gosto: prefiro mesmo as escolas de samba" (Artigo "Balanço de Carnaval" - Jornal O Dia Online).

Em (12), podemos observar o adverbial modalizador "exatamente". O artigo opinativo, escrito no contexto do carnaval carioca de 2016, apresenta uma relação entre a comemoração de ano novo e as festas carnavalescas. $O$ enunciador parece ter como objetivo deixar claro ("para ser exato") que prefere as escolas de samba ao carnaval em si e, por isso, utiliza o adverbial "exatamente". Esse termo, então, parece delimitar o que ele gosta, mas, ao mesmo tempo, apresenta um grau de certeza em relação ao que está sendo enunciado, o que faz com que seja tido como veiculador também de efeito epistêmico. No trabalho, consideramos que seu valor é delimitador, embora reconheçamos que há um grau de certeza no enunciado bem maior do que em outros casos de delimitadores como "historicamente" e "matematicamente". Com esse exemplo, queremos demonstrar que há uma fluidez 
categorial entre esses elementos e que eles podem, a depender do contexto enunciativo, apresentar distintos efeitos discursivos. Além disso, uma mesma categoria engloba elementos bastante diferentes e com graus de subjetividade também distintos. No entanto, acreditamos que seja possível estabelecer alguns postulados baseando-se, sobretudo, nos exemplos prototípicos dessas categorias.

Assim, podemos concluir que os modalizadores "infelizmente", "quase" e "exatamente" veiculam, de fato, efeitos de sentido subjetivos, mas apresentam graus diferentes. No exemplo (12), parece ser menos claro a um leitor que não atinja níveis de leitura mais avançados que o modalizador "quase" veicule subjetividade, enquanto os modalizadores "infelizmente" e "certamente" apresentam um posicionamento mais claro, veiculando maior grau de subjetividade. Dessa forma, postulamos que há categorias mais e menos subjetivas dentro do grupo dos adverbiais modalizadores e reconhecemos que, dentro desses grupos, há elementos mais e menos prototípicos. Ressaltamos, ainda, que não postulamos um continuum entre subjetividade e objetividade, pois, como mostram outros trabalhos, toda linguagem apresenta marcas subjetivas e veicula ideologia (cf. PAULIUKONIS, [2003] 2007; VAN DIJK, 2015).

Diante do continuum apresentado, verificamos quantitativamente quais eram os efeitos de sentido mais frequentes e seu grau de subjetividade para que pudéssemos relacionar à nossa hipótese. Obtivemos o seguinte resultado:

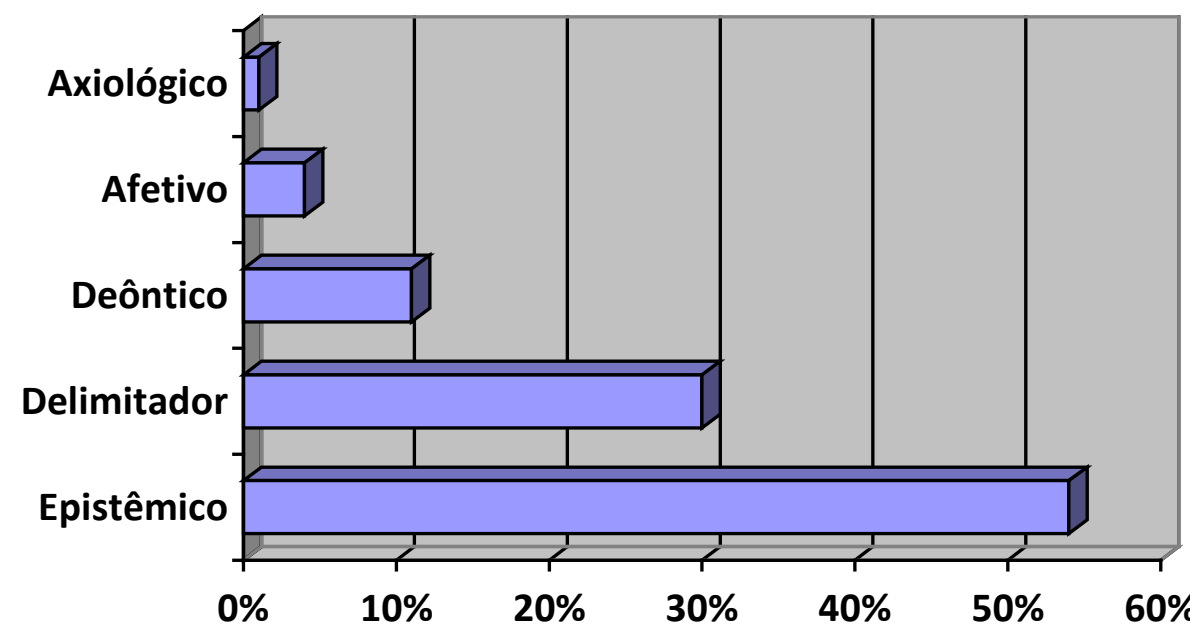

Efeitos de sentido

Gráfico 1: efeitos de sentido dos adverbiais modalizadores como articuladores textuais na amostra utilizada. Fonte: Castanheira (2017) 
Esse resultado demonstra que o efeito de sentido mais frequente na amostra do trabalho foi epistêmico (54\%). Esse uso está no meio do continuum de subjetividade postulado neste trabalho, o que confirma nossa hipótese de que os modalizadores usados são mais subjetivos. Acreditamos que o baixo número de dados com efeitos afetivo e axiológico possa estar vinculado ao gênero textual em que esses textos estão inseridos, tendo em vista que parecem ser mais características expressões de certeza (ou seja, aquelas ligadas ao efeito epistêmico) do que de afetividade nesse gênero e nesse suporte. Ou seja, acreditamos que a ausência de adverbiais modalizadores com efeito axiológico e afetivo não estaria ligada à menor expressão da subjetividade, mas a ser mais efetivo para os enunciadores demonstrar seu grau de certeza em relação ao assunto debatido, muitas vezes de cunho político, do que o uso de expressões que veiculem sentimentos e emoções de forma mais explícita.

Em outros suportes menos monitorados, como blogs ou facebook, textos desse gênero podem apresentar pistas textuais ligadas a outros efeitos de sentido. É preciso destacar, ainda, a ausência de adverbiais modalizadores como "com certeza" e "sem dúvida", bastante encontrados em outros trabalhos sobre o tema em outros corpora. Na fala, esses resultados indicam outras tendências (cf. CASTILHO; CASTILHO, [1992] 2002) e na escrita menos monitorada talvez modalizadores com efeito de sentido afetivo e axiológico possam ser mais utilizados. Esse confronto aponta para a necessidade de estudar os usos no continuum tipológico de Marcuschi (2001) com textos distribuídos em gêneros que vão desde a fala menos monitorada à escrita mais monitorada. Também é necessário destacar que boa parte dos adverbiais modalizadores apresentam efeito delimitador, considerado por nós o menos subjetivo, o que reforça o papel da linha editorial dos jornais $O$ Globo Online e O Dia Online e o suporte jornal de forma geral.

Esses resultados também podem ser explicados pelo princípio funcionalista da marcação: formas mais marcadas tendem a ser menos frequentes do que formas menos marcadas. Diante da existência de adverbiais modalizadores com diferentes efeitos de sentido, como demonstramos, acreditamos que os modalizadores afetivos e axiológicos tendem a ser mais marcados nesse aspecto, o que levaria a sua baixa frequência em textos desse gênero nesse suporte. Por isso, formas que são menos marcadas ("historicamente", "tecnologicamente", "matematicamente") ocorreriam com maior frequência do que as formas mais marcadas ("infelizmente", "felizmente", 
"com certeza").

Em relação à distribuição dos modalizadores quanto aos seus efeitos de sentido nos jornais, apresentamos o gráfico a seguir:

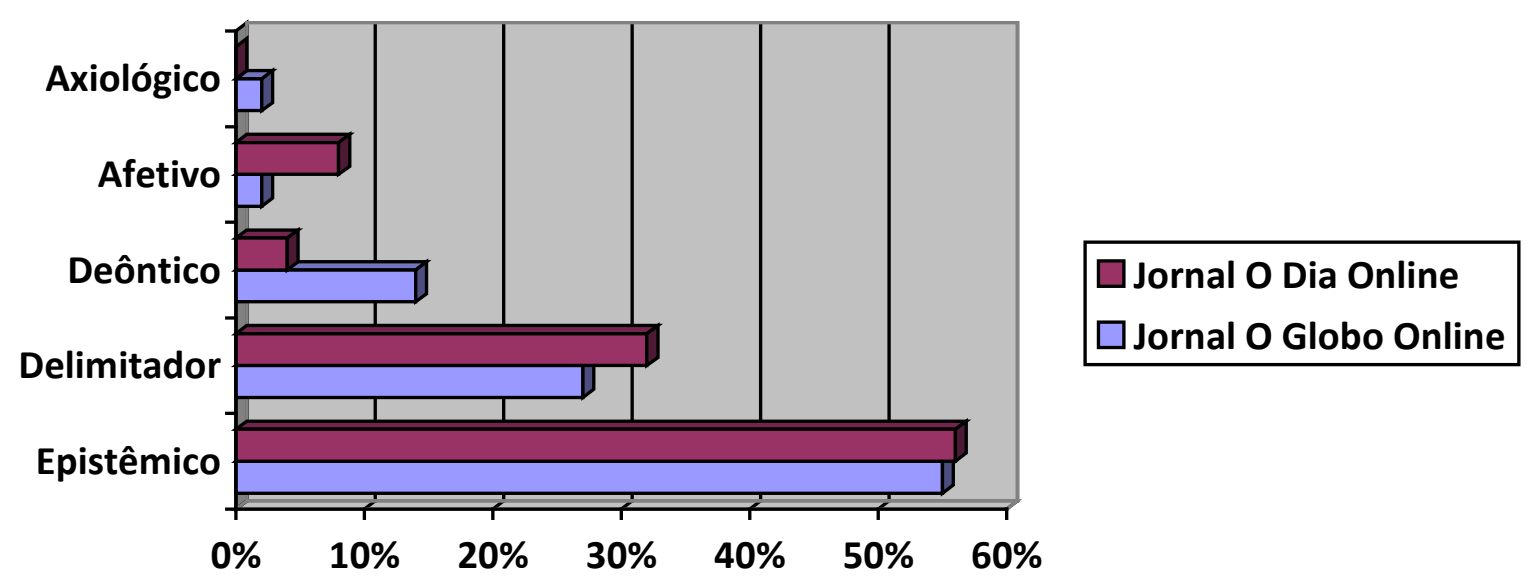

Gráfico 2: relação entre efeitos de sentido dos adverbiais modalizadores e os jornais utilizados. Fonte: Castanheira (2017)

A partir desse gráfico, podemos observar que não há diferenças significativas nos dois jornais, o que parece demonstrar uma aproximação entre eles. Mesmo tendo públicos-alvo distintos, os efeitos dos modalizadores foram basicamente os mesmos. A diferença quantitativa está no maior uso de adverbiais com efeito deôntico em $O$ Globo Online e a existência de um modalizador afetivo a mais em $O$ Dia Online. A diferença de um dado não apresenta grande valor estatístico, mas, se combinada com a baixa frequência de afetivos, corrobora a argumentação apresentada anteriormente de que esses usos são pouco frequentes devido ao suporte. O maior uso de modalizadores com efeito deôntico pode ser explicado pelo constante uso do modalizador "necessariamente" por alguns articulistas, o que pode ter causado a diferença quantitativa dos resultados.

Ao longo desta subseção, observamos o uso dos adverbiais modalizadores em artigos opinativos dos jornais $O$ Globo Online e O Dia Online. Em relação aos efeitos de sentido, percebemos a predominância do efeito epistêmico, o que atribuímos a características do gênero e do suporte da amostra, e a existência de um continuum de subjetividade em relação aos efeitos vinculados aos adverbiais modalizadores. 


\section{Considerações finais}

Analisamos, com base no Funcionalismo norte-americano e na Linguística do Texto, os efeitos de sentido e os graus de subjetividade envolvidos no uso dos adverbiais modalizadores. Primeiramente, retomamos os estudos sobre esses elementos, como expusemos na seção 1 deste artigo, e, posteriormente, a partir dos dados encontrados, estabelecemos uma categorização dos efeitos de sentido, estabelecendo uma proposta de reclassificação. Após esse processo, observamos que esses grupos apresentavam diferentes graus de subjetividade e que poderíamos estabelecer um continuum entre eles.

Diante desse continuum, controlamos quantitativamente a frequência dos efeitos de sentido e percebemos que o efeito deôntico é o mais frequente nos artigos opinativos analisados, o que relacionamos com um uso subjetivo e ligado à expressão de certeza/ incerteza em relação à proposição, algo constitutivo desse gênero. Além disso, observamos que os veículos utilizados na análise também não influenciaram em relação a esse aspecto do uso dos adverbiais modalizadores, ou seja, em relação aos seus efeitos de sentido/ subjetividade.

Este artigo, então, apresenta como principais contribuições o mapeamento qualitativo dos efeitos de sentido dos adverbiais modalizadores relacionados aos graus de subjetividade e a análise qualitativa e quantitativa dessa relação em uma amostra de dados reais de uso. Além disso, demonstra que os agrupamentos pragmáticos são fluidos e devem ser considerados a partir do contexto, o que inclui aspectos como gênero, suporte e veículo. Alguns próximos passos para estudos da área são: a análise de outros aspectos pragmáticos relacionados à subjetividade, a utilização de outras amostras para fins comparativos e a busca de sugestões de atividades para a educação básica, considerando os resultados encontrados (cf. SANTOS; CASTANHEIRA, inédito).

\section{Referências}

BAKHTIN, M. Os gêneros do discurso. In: BAKHTIN, M. Estética da criação verbal. Traduzido por Maria Ermantina Galvão Pereira. São Paulo: Martins Fontes, 1997 [1979], p. 261-306.

BENVENISTE, E. Problemas de linguística geral I. Traduzido por Maria da Glória 
Novak e Luiza Neri. São Paulo: Ed. Nacional, 1976.

BOFF, O. M. B.; KÖCHE, V. S.; MARINELLO, A. F. O gênero textual artigo de opinião: um meio de interação. ReVEL, vol. 7, n. 13, 2009.

BRÄKLING, K. L. Trabalhando com artigo de opinião: re-visitando o eu no exercício da (re)significação da palavra do outro. In: ROJO, R. (org.). A prática da linguagem em sala de aula: praticando os PCN. São Paulo: EDUC; Campinas, SP: Mercado de Letras, 2000, p. 221-247.

CAMPOS, C.; TORQUATO, C. P. Articulação. In: COSTA, I. B.; FOLTRAN, M. J. (orgs.). A tessitura da escrita. São Paulo: Contexto, 2013, p. 124-144.

CASTANHEIRA, D. Uso de adverbiais modalizadores e sua abordagem em livros didáticos de ensino médio: reflexões e propostas de atividades. 119 f. Dissertação (Mestrado em Linguística). Rio de Janeiro: Faculdade de Letras, Universidade Federal do Rio de Janeiro, Rio de Janeiro, 2017.

CAVALCANTE, M. Os sentidos do texto. São Paulo: Contexto, 2011.

CEZARIO, M. M. et al. Os advérbios. In: CASTILHO, A.; LOPES, C. R. Mudança sintática das classes de palavra: perspectiva funcionalista - história do português brasileiro. São Paulo: Contexto. No prelo.

GIVÓN, T. Syntax: a functional-typological introduction. Amsterdam/ Philadelphia: John Benjamins, 1990.

GIVÓN, T. Functionalism and grammar. Amsterdam/Philadelphia: John Benjamins, 1995.

ILOGTI DE SÁ, E. C. Aconteceu em 2015 e en 2015 il est arrivé: ordenação dos circunstanciais temporais e aspectuais no português e no francês. 2015. $222 \mathrm{f}$. Tese (Doutorado em Linguística). Rio de Janeiro: Faculdade de Letras, Universidade Federal do Rio de Janeiro, 2015.

KOCH, I. V. Desvendando os segredos do texto. São Paulo: Cortez, 2003.

$\mathrm{KOCH}$, I. V. Introdução à Linguística Textual: trajetória e grandes temas. 2. ed. São Paulo: Contexto, 2015 [2004].

MARCUSCHI, L. A. Da fala para escrita: atividades de retextualização. São Paulo, Contexto, 2001.

MARCUSCHI, L. A. Produção textual, análise de gêneros e compreensão. São Paulo: Parábola Editorial, 2008.

MARTELOTTA, M. E. Advérbios: conceitos e tendências de ordenação. In: OLIVEIRA, M. R.; CEZARIO, M. M. (orgs.). Adverbiais: aspectos gramaticais e pressões discursivas. Niterói: Editora da UFF, 2012. p. 13-96. 
MELO, B. O. R. Gêneros textuais e argumentação: propostas de ensino do artigo de opinião em livros didáticos. Linha D’Água (Online), São Paulo, v. 28, n. 2, p. 67-84, dez 2015.

PAULIUKONIS, M. A. Marcas discursivas do enunciador midiático: casos de modalização autonímica. In: PAULIUKONIS, M. A.; GAVAZZI, S. Texto e discurso: mídia, literatura e ensino. 2. ed. Rio de Janeiro: Lucerna, 2007 [2003], p. 38-50.

SANTOS, L. W. Articulação textual na literatura infantil e juvenil. Rio de Janeiro: Lucerna, 2003.

SANTOS, L. W.; CASTANHEIRA, D. Leitura e modalização no ensino: análise de artigo de opinião. Inédito.

TRAUGOTT, E. C. (Inter)subjectivity and (Inter)subjectification: a reassessment. In: DAVIDSE, K.; VANDELANOTTE, L.; CUYCKENS, H. (org.) Subjectification, intersubjectification and grammaticalization. Berlin/New York: Walter de Gruyter, 2010, p. 29-71.

TRAUGOTT, E. C.; DASHER, R. Regularity in semantic change. Cambridge: Cambridge University Press, 2002.

VAN DIJK, T. Cognitive context models and discourse. In: STAMENOW, M (ed.). Language Structure, Discourse and the Access to Consciousness. Amsterdam: Benjamins, 1997, p. 189-226.

Recebido em 21/09/2017

Aceito em 17/10/2017

Publicado em 20/12/2017 